\title{
A study on local knowledge in adaptation to landslide disasters in Sri Lanka
}

\author{
Uditha Dasanayaka ${ }^{a}$ and Yoko Matsuda ${ }^{b, *}$ \\ Department of Civil \& Environmental Engineering, Nagaoka University of Technology, Japan \\ E-mail: auditha05@gmail.com, bymatsuda@vos.nagaokaut.ac.jp (Corresponding author)
}

\begin{abstract}
Natural disasters are unforeseen events which occur at hydrologic, geologic, and atmospheric origins. The Policy-makers still rely on mitigation strategies based on scientific approaches. However, many scholars had emphasized the importance of incorporating local knowledge and related practices for disaster risk management. In that context, this study investigates the local knowledge in adaptation to mitigate the landslides disaster situations by studying a village in Sri Lanka which is located at the central region of Sri Lanka which is vulnerable for landslide disasters. Landslides is one of the severe types of disasters in hilly terrains and which cause to loss of lives and property damages especially in Asia region. This study employed the field surveys, questionnaire surveys and semi structured interviews for data collection. The findings of the research indicate how the local knowledge-based practices in settlement layout \& planning, landscaping had enhanced disaster adaptation level of the community. Further the local knowledge-based value systems act as a strong mechanism in identifying early signs of landslide disasters. Finally, the paper discusses the possibilities of upscaling such local practices for mainstream disaster management practices.
\end{abstract}

Keywords: Landslides, local knowledge, adaptation, semi structured interviews.

ENGINEERING JOURNAL Volume 23 Issue 6

Received 3 April 2019

Accepted 10 June 2019

Published 30 November 2019

Online at http://www.engj.org/

DOI:10.4186/ej.2019.23.6.501 


\section{Introduction}

The progressive increase of human activities in accordance with the rapid growth of population lead to complex and inter-linked environmental and societal worldwide issues. Natural disasters and climate change becomes the most common issues and the consequences are extremely diverse. Major disasters such as flood, landslide, earthquake, tsunami, and drought etc. are perplexing for prior prediction and can result the environmental degradation by reducing the capacity of environment to attain social and ecological needs. In many parts of the world, landslides/earth slips had become a major type of disaster which is triggered due to natural and human induced reasons. The downward movement of slope-forming material such as soil, boulder, weather rock, intact rock and composition of them, along with groundwater and surface water, driven by gravity and triggered by rise of groundwater, and/or other factors such as erosion and rainfall form the landslide. Depending upon the material, speed and form of movement, the relation with water, type of terrain it occurs, and the size or scale, landslide can be classified into various groups. Specifically, a landslide can be grouped into different types as falls, topples, slides, lateral spreads, flows, mass movements, creeps, collapse, cutting failures, rock falls, and complex of them [1].

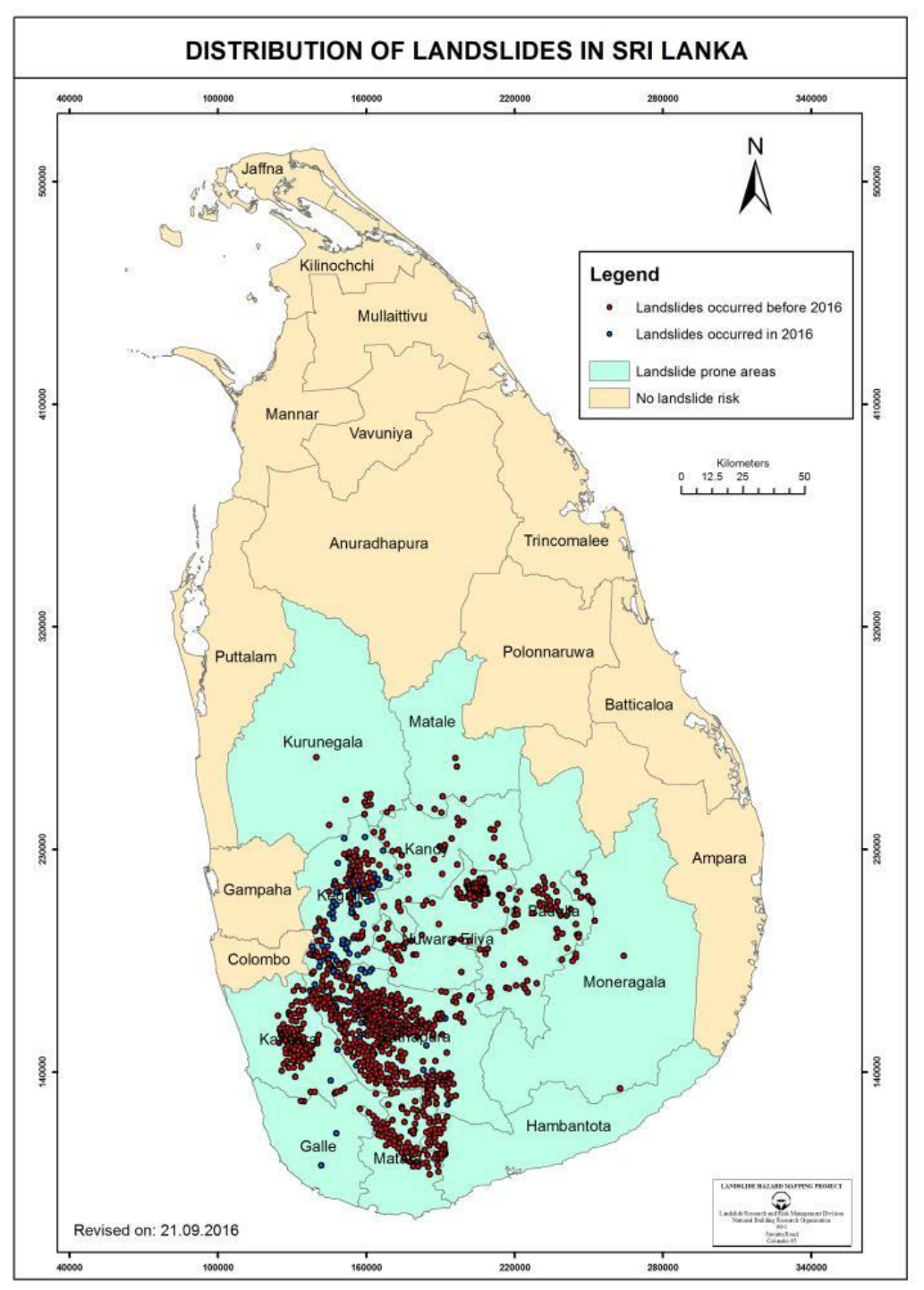

Fig. 1. Distribution of landslides occurrence before September 2016, in Sri Lanka.

In the recent years, landslides, floods and droughts are identified as most frequent and critical type of natural disasters in Sri Lanka [2]. Landslides are the most common and significant in central hilly terrains. 
Badulla, Nuwara Eliya, Ratnapura, Kegalle, Kandy, Matale, Kalutara Districts located in the central hills region and Matara, Galle and Hambanthota Districts in the southern hills are identified as the landslide prone areas while approximately $20,000 \mathrm{~km} 2(37.7 \%)$ of land area is highly vulnerable for landslides. With gradual growth of demand in the development and expansion of human settlements, landslides play the major concern for the country's mountainous regions [3]. The rate of incidences and frequency of landslides are increasing. The density of the current landslide is estimated at around 1 to 2 landslides per square kilometre. Each and every rain, it is ordinary to happen one or two landslides or cutting failures. Landslides in Sri Lanka occurred not only due to natural causes but due to man-made causes [1]. Figure.1 shows the main landslide records up to the year 2016. The landslide disasters become the main threat to the countries like Sri Lanka. Therefore, identification of best solutions for minimizing landslide risk associated with the terrain is important for ensuring the sustainability of developments while minimizing the possible disasters due to landslides.

The contribution of indigenous local knowledge is the effective and useful disaster risk reduction intervention for identifying, assessing and monitoring disaster risks and enhancing the early warning for disaster risk reduction activities at the local level. Local knowledge contributes the large body of knowledge and skills developing at the outreach of the formal educational system [4]. The practice of using local knowledge is embedded in the society as a culture for long period of time. It helps and provides the basis for planning and decision-making for communities as in food securing, human and animal health, educational and natural resource management.

The practices of using indigenous knowledge as an early warning indicators for natural disasters are still widely used [4]. However, the Policy-makers still rely on mitigation strategies based on scientific approaches [5]. But some isolated mountain villagers still survived without any landslide damages with their local knowledge-based adaptations. Although there are more details about indigenous knowledge mitigations, the wealth of this knowledge has not been well-recognized in the process of disaster risk reduction. In addition, the scientific documentary evidences in Sri Lanka are very limited.

According to landslide risk levels, there are mainly three categories, high, moderate and low landslide risk zones. In high risk zones, the possibility of occurring the large-scale landslide is high and according to the records of the affected area recently suffered from it, it destroyed all settlement without remaining any object. Furthermore, the only possible solution for the affected areas having the high landslide risk is to abandon their area and move to the new location. However, the areas having the moderate level of risk may reduce the extent of vulnerability by practicing the effective landslide mitigation actions. This research is an attempt to investigate the local knowledge in adaptation to mitigate the landslide disaster situations based on moderate level landslide risk zone is described. These types of studies mainly use the reference with the case study approach [6]. For the study, Etanwala village in central region of Sri Lanka was selected for investigating their adaptation to landslide disasters.

The next section of the paper provides a detail account of the case study area and survey approach used in the research. Third section of the paper discuss how local knowledge-based practices enhanced the adaptation level of the community in dealing with different levels of disaster management cycle. Further latter part of the section discusses the possibilities of up scaling such local knowledge for mainstream disaster management practices. Final section concludes the main findings of the research while keeping a brief note on further research agenda.

\section{Methodology}

\subsection{Case Study Area}

The research study was conducted in one geographically isolated village named "Etanwala" in Matale District of Sri Lanka. This village is located in the central hilly region with a total population of 154 lived in $42 \mathrm{~km} 2$ administratively bounded region. This study area is under the moderate landslide risk zone.

This area has poor transportation system to get access easily. More than half of the area of the village is occupied by the cultivation about $84 \%$. Around $14 \%$ of the area is with the forest and only $2 \%$ is covered with housings. There is one main river called Kalu Ganga Black River that is the main water source of the village for cultivation and domestic purposes. The river is separated the village with other area and only has three number of 3 -m wide village to cross. 


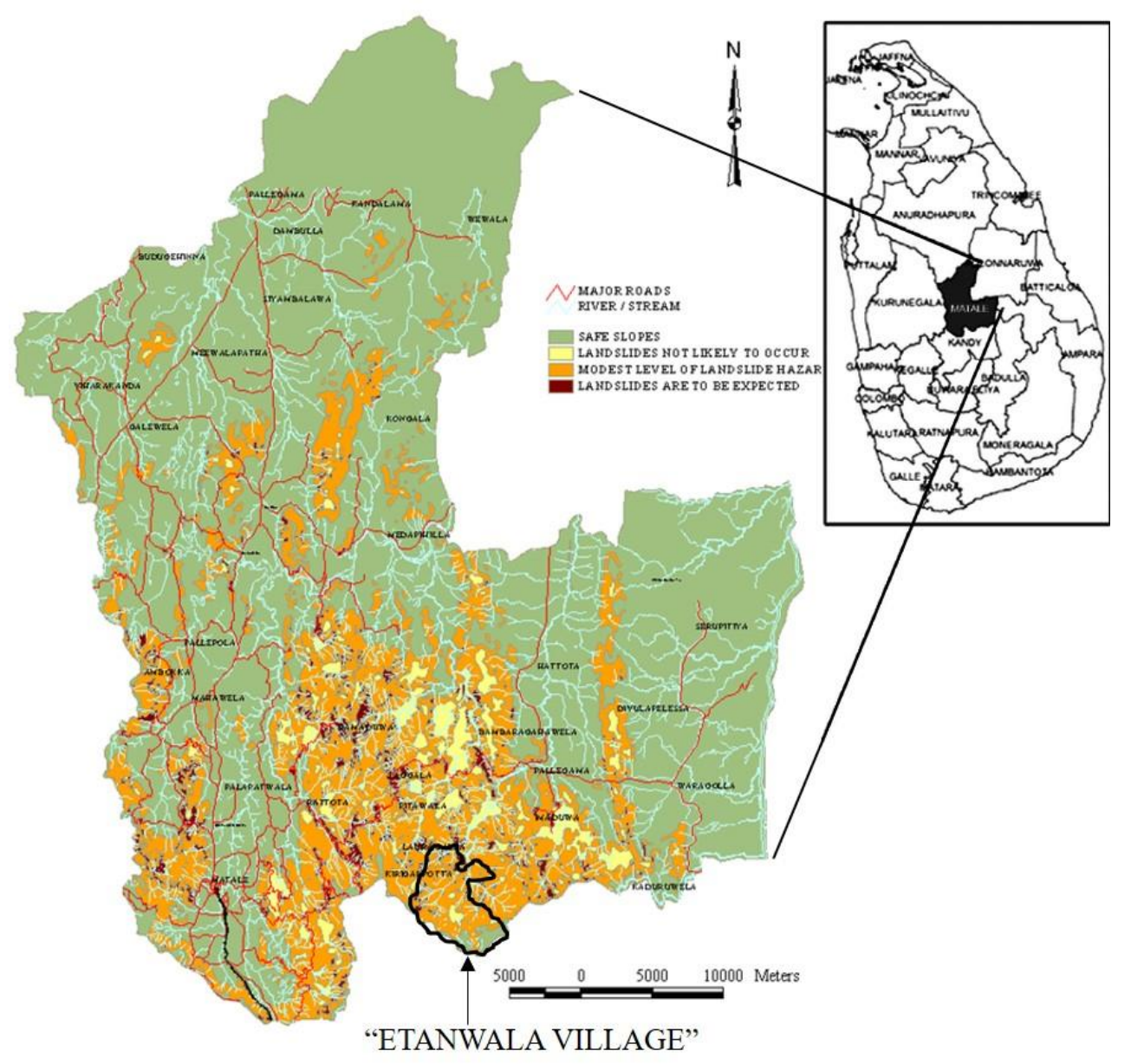

Fig. 2. Map of landslide hazard zones in Matale district Sri Lanka.

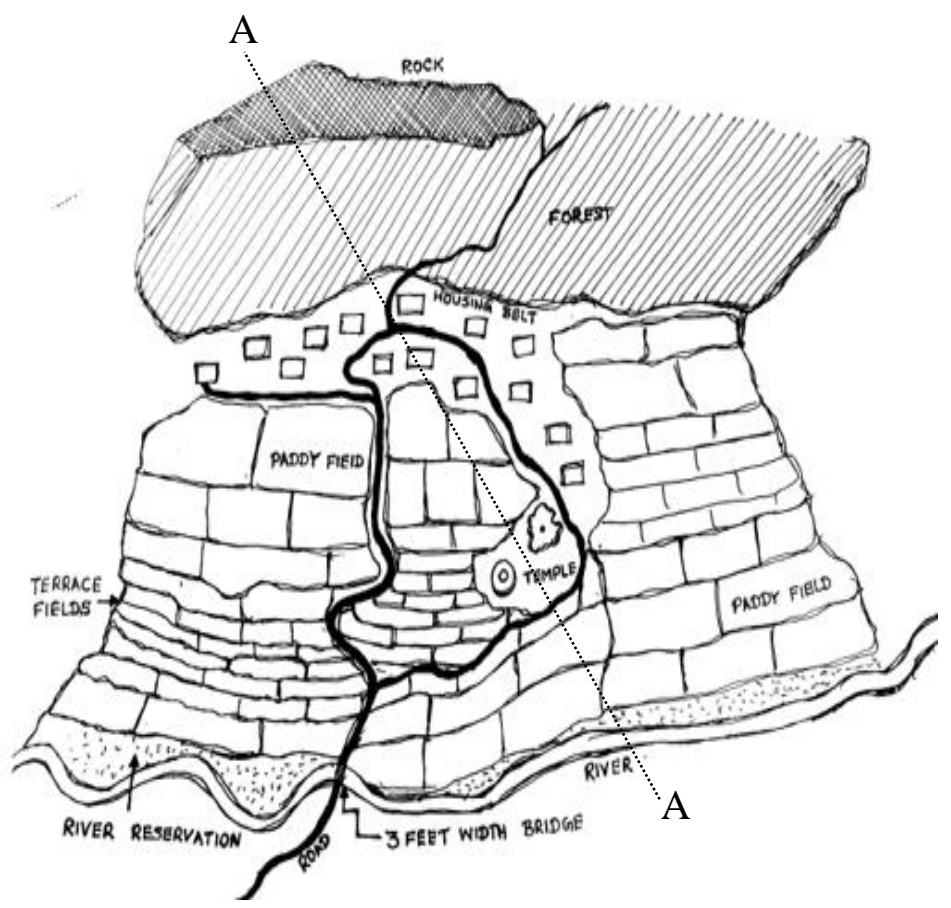

Fig. 3. Etanwala village layout integrating the forest, the temple, the terrace fields, and homestead. Conceptual. Source: Author. 


\subsection{Survey Method}

For this study, the 80 sample population was selected using the snowball sampling technique [7] and conducted a questionnaire survey. The sample included four categories of villages based on their age, 10 candidates from 12 to 19 years age group, 22 from 20 to 39 years age group, 25 from 40 to 59 years age group and 23 candidates from more than 60 years old group who are dwelling in this village. Reason for carrying out the micro level study was to ascertain village's utility of their local knowledge on landslide disaster risk reduction. Since it does not completely capture all features of the local adaptations, semistructured interviews were conducted with selected elders as well as with some relevant government officers. Percentage analysis was used to analyze the data.

\section{Results and Discussion}

For Eight local knowledge-based practices/actions related to landslide risk reduction were identified (Table 1). The respondents had known all the local knowledge-based practices by their own experiences.

More than three-fifths $(69 \%)$ of villages are aware of the landslide risk that incurred in their life being in this isolated village. Two different observations actions were identified for the landslide risk prediction. Little more than one third $(34 \%)$ of villages are aware of the unusual earth cracks are one best pre-indicator for landslide. While little more than four-fifths of villages were responded as continuous heavy rain may cause landslides. Early warning system is an essential component in disaster risk reduction. The village itself has a special method of passing emergency massages. It is embedded in their culture and more than fourfifths $(93 \%)$ of villages are aware of the warning system based on temple bell.

Table 1. Level of awareness on adaptation actions.

\begin{tabular}{|l|c|c|}
\hline \multirow{2}{*}{ local knowledge based practices/actions } & \multicolumn{2}{|l|}{ Respondents ( NO 80) } \\
\cline { 2 - 3 } & Number & $\%$ \\
\hline Basic awareness on Landslides & 55 & $69 \%$ \\
\hline Unusual earth cracks & 27 & $34 \%$ \\
\hline Continuous heavy rain & 70 & $87 \%$ \\
\hline Warning system based on temple bell & 74 & $93 \%$ \\
\hline Practicing "Aththam Kramaya" & 38 & $47 \%$ \\
\hline Terrace paddy fields / Forest reservation & 46 & $57 \%$ \\
\hline Live fencing & 64 & $80 \%$ \\
\hline Stone walls & 66 & $83 \%$ \\
\hline
\end{tabular}

\subsection{Basic Awareness on Landslides}

Out of different types of natural disasters, landslides are the main disaster that occur frequently and having high potential to occur in this village. This village experienced small-scale landslides during past few years and the warning about the main landslide targeting to the part of the village was issued by National Building Research Organization. Based on above incident, most of the villages are well-aware about the landslide disasters and its initial phenomenon.

\subsection{Early signs for Landslides}

Nowadays, disaster prediction methods are effective and efficient with the most advanced technologies. But, the developing countries are still facing with the difficulties of accessing high technologies for disaster prevention program. In this case, the local knowledge regarding the early signs is very reliable and practical solutions for the local people. In this research, two main types of early signs regarding with the disaster prevention used by communities for the landslides are identified. The first type is unusual earth cracks which can be easily observed by checking the newly occurred cracks on ground. Using the above knowledge of early signs, local people can assume the area as high potential to landslides. The second one, continuous heavy rainfall, can make the changes to the ground water table by increasing the risks of severe landslides. The local people get cautions for the risks of landslide as soon as they notice the heavy continuous rainfall phenomenon for three or four days. 


\subsection{Warning System Based on Temple Bell}

The villagers have strong beliefs in cultural system. They all inherited all the beliefs and behaviors within their group and respect them. Temple is one of the most important and sacred place as religious beliefs for the group to deliver the important messages and decisions to them. Therefore, they use temple bells to give early prevention signs by ringing the bells. As the temple is located at the center of the area, the people can get easy access to the place and escape from the risks of the disaster when they notice the sound of the bells for emergency disaster prevention case.

\subsection{Practicing “Attam kramaya” (Farming together)}

This is derived from the traditional practices. Their main living depends upon cultivation of paddy and vegetables. As they always practice farming by gathering and working together, they can transfer their practices as the tacit knowledge. They always use this method effectively from one generation to another since many years ago. Therefore, the knowledge based on disaster prevention can transfer through this practice.
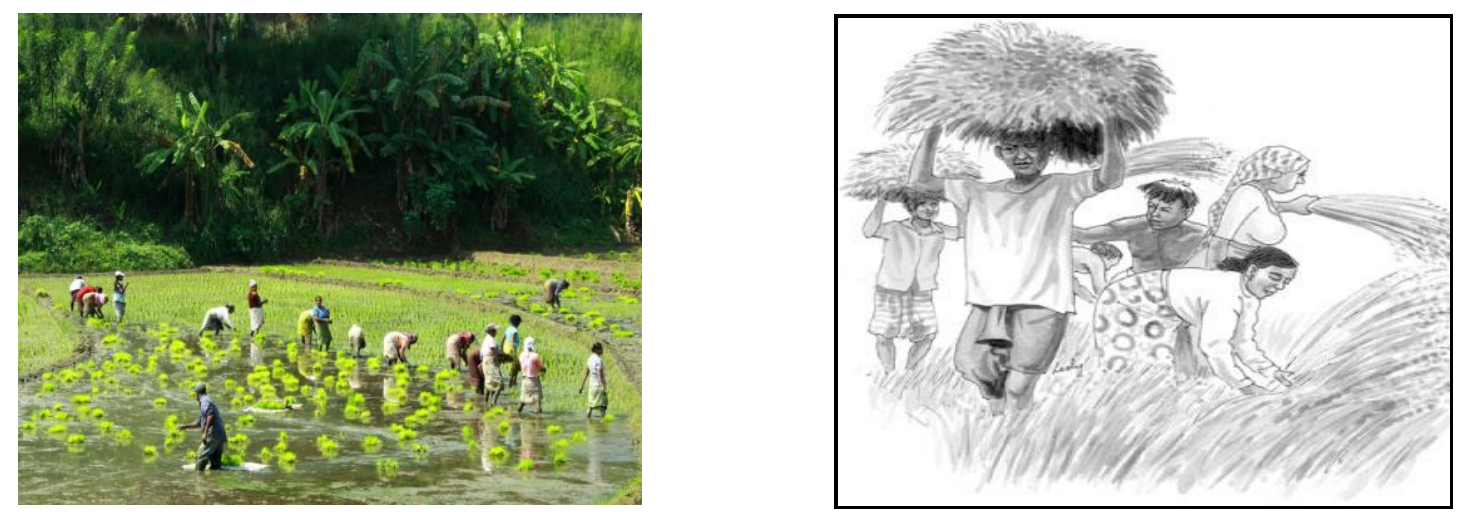

Fig. 4. Farmers planting paddy in waterlogged fields in Sri Lanka, Source: (Photo: cc: Denish C on Flickr) / Daily News Sri Lankas national newspaper 1918.

\subsection{Specific Land Use Pattern}

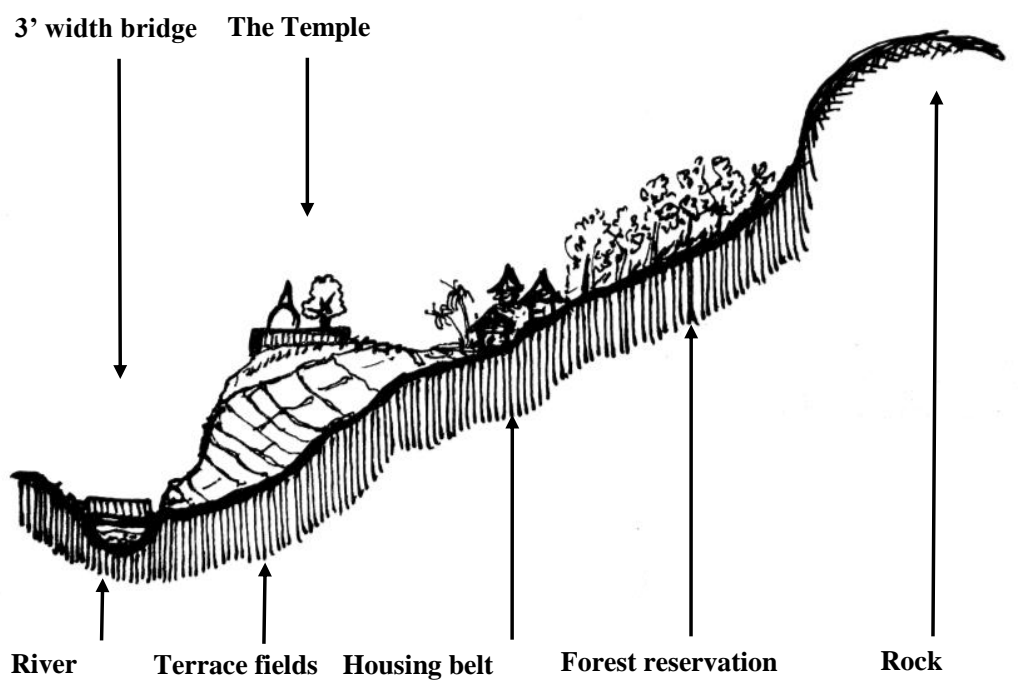

Fig. 5. Farmers Etanwala village profile, cross section of the village profile (Section A-A in Fig. 3) Source: Author 
The respondents especially highlight effective pattern of land uses to prevent from the landslide hazard. Reservation of forest is one of the practices for the landslide hazards. Villagers reserve the forest in the upper region to prevent from the landslide. Specially, they plant and reserve the tree belts near their house in the upper side from the rock falls.

They built their houses in the uniform pattern within the belt to prevent deforestation. During the survey, they mentioned that terrace cultivation method is the most effective way for the prevention of landslide risks. As shown in Figure 5, the villagers are still using this specific pattern of reserving the forests in the upper slope and cultivating the paddy fields in the terrace pattern in the lower part in order to prevent the landslides.

\subsection{Life Fencing and Stone Walls}

Improving the soil strength and reducing soil erosion and also preventing landslide failure due to slope cutting, they use two types of techniques, life fencing and stone walls. For the life fencing, they use specific type of medicinal plant called Pawatta, Justicia adhatoda. It not only reduces landslide risks but also provides the indirect medicinal benefits. For the stone walls, they use their own techniques and use cost effective local materials. Those two methods have their own benefits and are easy to apply in local community.
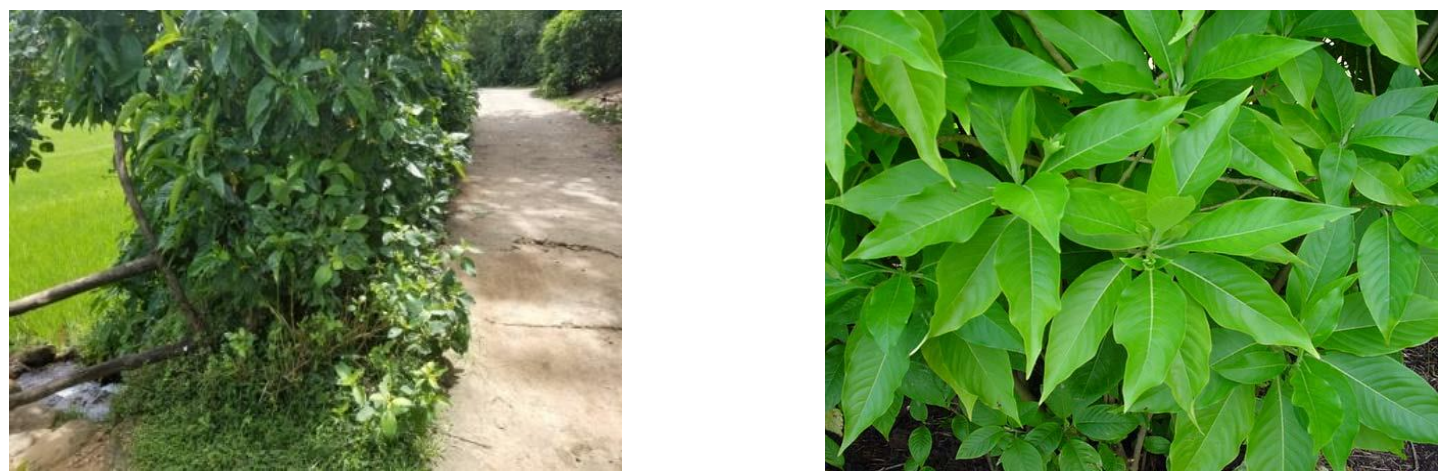

Fig. 6. Pawatta plant used for making live fences.Source: Author.
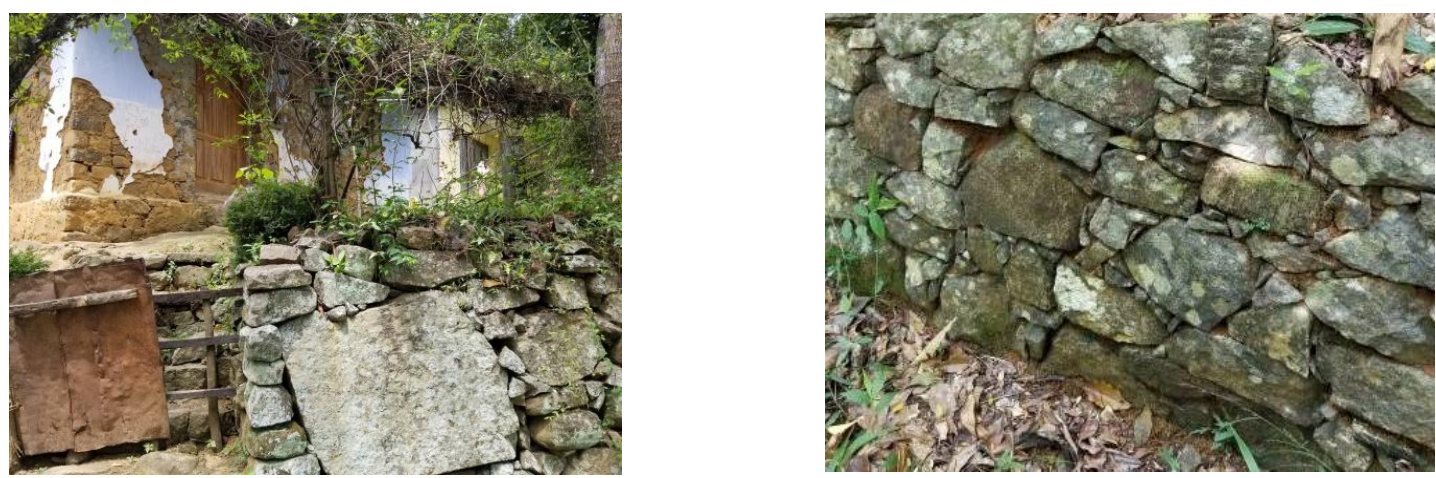

Fig. 7. Retaining Walls. Source: Author.

From this survey, the eight actions are categorized and identified clearly for reducing the landslide risks for this community. These actions can provide advantages for the community and the awareness of these actions vary depending upon the Age groups. The following graph shows the different level of awareness for four Age groups.

Comparatively low awareness on "Unusual earth Cracks" in all four age groups with compared to other adaptation actions is shown in the figure 8. High awareness on both "Continuous heavy rain" and "Warning system based on temple bell" in all four Age groups with compared to other adaptation actions are described in the above graph. Age group of 12-19 years have very low awareness for all actions other 
than "Continuous heavy rain" and "Warning system based on temple bell". As overall, the Age group over 40 years have comparatively high awareness on all type of adaptation actions.

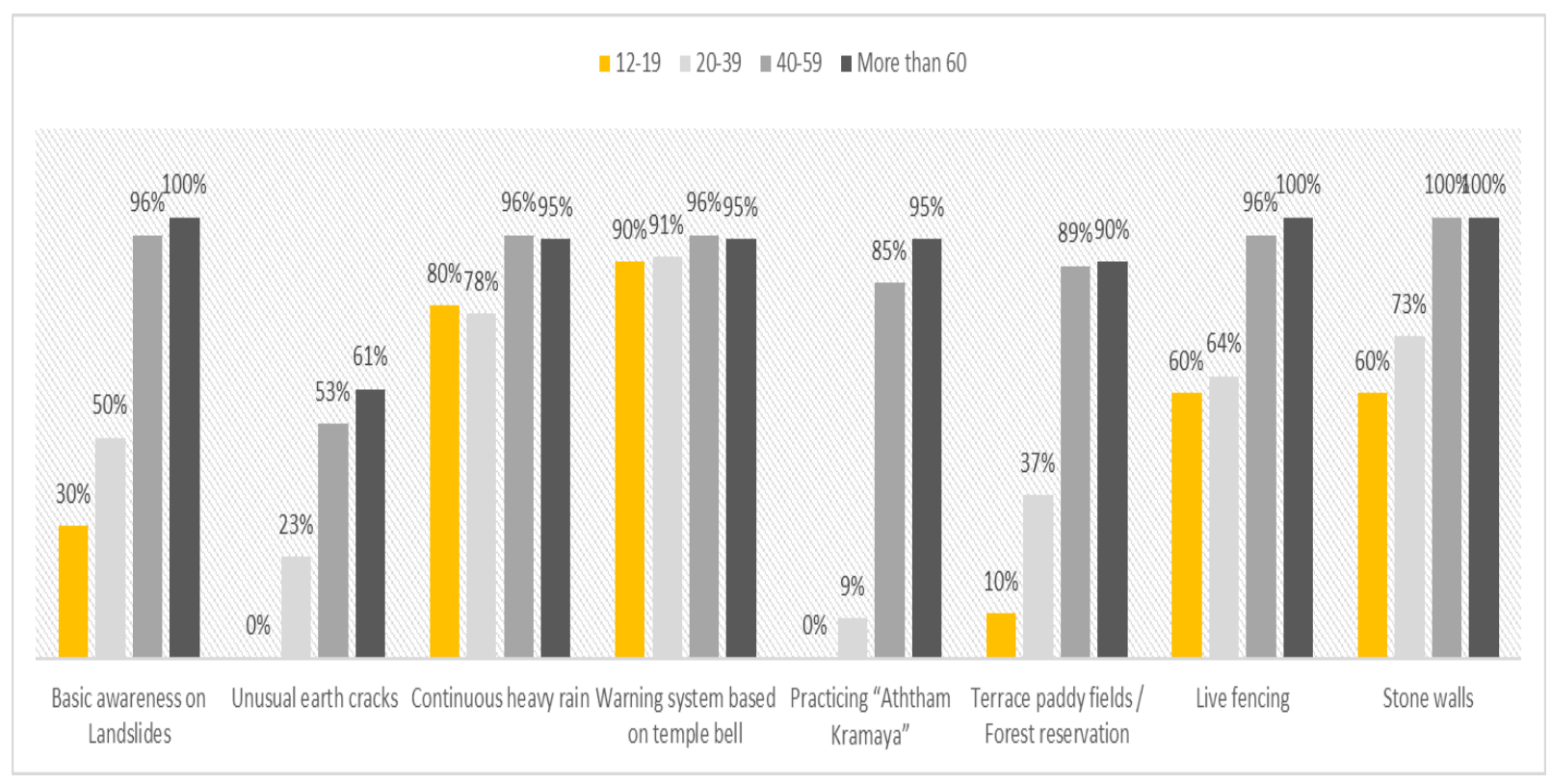

Fig. 8. Level of awareness on adaptation actions varied with different age groups, Source: Author.

\subsection{How 'Etanwala' Become Sustainable in the Landslide Disaster Context?}

This community is living at a geographically isolated village in landslide prone area of Sri Lanka. However, they still enhanced their adaptation level to live without suffering from a major landslides disaster. Their main income is based on agriculture. They accomplish all the necessary sources from their own land [8].

It is well recognized fact that the main cause of landslides in Sri Lanka is due to human induced reasons [9], mainly the poor land use practices. In that context, it is evident from the survey findings that this community is consciously aware of the possible consequences that may arises from poor land utilization. Around $75 \%$ of the people in the area aware about the landslide risks and they always use landslide prevention practices when they aim to change the land use such as life fencing and stonewall for reducing soil failure. Further they adapt a unique land utilization pattern which prevent the probable landslide risks. They maintain the land area into three portions, the upper area as forest reservation, the middle portion high above the flood plain area, as concentrated housings surrounded by tree belts, the lower area as the paddy fields in the terrace pattern having the benefits to prevent severe landslides.

In addition, the overall awareness of the possibilities of landslides can be recognized as a tacit knowledge which transfer from one generation to another as a part of their value system.

\subsection{How Can We Use this Case Study Findings in Improving Contemporary Disaster Landslide Prevention Practices?}

This In an era, which many parts of the world are facing the adverse effects of climate change [6], countries like Sri Lanka at the middle-income range always find the difficulties in establishing scientific based hightech solutions for disaster management [10]. Further in most cases the usability of such initiatives are in vain due to the difficulties in embedding such solutions to the community level value systems.

The overall consequences of this do not stands positively in overall disaster risk management process. This is never to undermine or under estimate the usefulness of such initiatives. In that context it is vital to recognize local knowledge-based adaptation practices and integrate them with scientific solutions to enhance the overall adaptation level for disasters. In overall context, such hybridization will yield more sustainable benefits than standalone scientific or local knowledge-based practices.

More specifically this study revealed the possibility of incorporating such approach in dealing with very complex and unpredictable types of disasters including landslides. 


\section{Conclusion}

As it is revealed in the third section of this paper, $69 \%$ of villagers are aware of the landslide risk that incurred in their life being in this isolated village. Further 34\% of the population are aware of the unusual earth cracks are one best pre-indicator for landslide, while little more than four-fifths of villages were responded as continuous heavy rain may cause landslides. $93 \%$ of villagers are aware of the warning system based on temple bell. However, comparatively low awareness on "Unusual earth Cracks" in all four age groups with compared to other adaptation actions. High awareness on both "Continuous heavy rain" and "Warning system based on temple bell" in all four Age groups with compared to other adaptation actions. 12-19 years have very low awareness for all actions other than "Continuous heavy rain" and "Warning system based on temple bell". As overall, the Age group over 40 years have comparatively high awareness on all type of adaptation actions.

Overall findings imply how the local knowledge-based practices and value system had enhanced the disaster resilience of this small community for landslide disasters. Further, the lesson learnt from the case study shed light for further research and for developing hybrid approaches which comprised of local knowledge and scientific knowledge in managing the risk of landslide disasters.

Future step of this research intends to develop a comprehensive operational framework to implement hybrid approach based on scientific interventions and local knowledge-based practices in landslide disaster management. It is expected to carry out several case studies to investigate further best practices to achieve the said goal.

\section{References}

[1] C. Agency, "The data collection survey on road protection against natural disaster (landslidedisaster)," Final Report (1/2), 2012.

[2] U. Ratnayake and S. Herath, "Changing rainfall and its impact on landslides in Sri Lanka," J. Mt. Sci., vol. 2, no. 3, pp. 218-224, Jan. 2005.

[3] H. Hemasinghe, "Landslide susceptibility mapping using logistic regression model (a case study in Badulla District, Sri Lanka)," Procedia Engineering, vol. 212, pp. 1046-1053, 2018.

[4] N. Anandaraja, T. Rathakrishnan, M. Ramasubramanian, P. Saravanan, and N. S. Suganthi, "Indigenous weather and forecast practices of Coimbatore district farmers of Tamil Nadu," Indian J. Tradit. Knowl., vol. 7, no. 4, pp. 630-633, 2008.

[5] E. J. Van Rensburg, E. Neluvhalani, and L. M. Van Damme, Indigenous Knowledge. 2002, pp. 1-43.

[6] A. Pareek and P. C. Trivedi, "Cultural values and indigenous knowledge of climate change and disaster prediction in Rajasthan, India," Indian J. Tradit. Knowl., vol. 10, no. 1, pp. 183-189, 2011.

[7] R. Dayaratne, "Toward sustainable development: Lessons from vernacular settlements of Sri Lanka," Front. Arcbit. Res., vol. 7, no. 3, pp. 334-346, Aug. 2018.

[8] J. F. Audefroy and B. N. C. Sánchez, "Integrating local knowledge for climate change adaptation in Yucatán, Mexico," Int. J. Sustain. Built Environ., vol. 6, no. 1, pp. 228-237, 2017.

[9] J. D. Rogers, Landslide Mitigation Techniques Landslide Repair. 2014.

[10] M. N. Uddin and M. M. Rahman, "Traditional ecological knowledge on flow and erosion processes in the braided Jamuna river in Bangladesh: Part-I," Indian J. Tradit. Knowl., vol. 12, no. 3, pp. 418-426, 2013. 